\title{
AN ANALYSIS OF QUALITATIVE PARAMETERS TO ENRICH STUDENTS' PERFORMANCE FOR IMMINENT POST GRADUATE COURSE SELECTION
}

\author{
Priti Shailesh Patel* \\ Research Scholar \& Assistant Professor, Department of Computer Science, \\ Shree RamkrishnaInsti. of comp edu. \& applied sciences, surat \\ Priti_patel22@hotmail.com \\ Dr. Dharmendra Bhatti \\ Supervisor \& Professor, Department of Computer Science, SRIMCA \\ UkaTarsadia University, Bardoli \\ dgbhatti@utu.ac.in \\ Dr. S.G.Desai \\ Co-supervisor \& Professor, Department of Computer Engineering, \\ SAL Engineering Institute, Ahmadabad \\ Subhash1948@yahoo.com
}

\begin{abstract}
This Recent era many educational data are using by researchers for fining hidden pattern of students learning ability, students' academic performance, student's behaviour towards study and so many issues solved with using data mining techniques. This paper study focuses on parameters which mostly affect the decision of students for selecting the post graduate course. There are also other numerous factors to consider, from the university and its location, course information published by institute, reputation of institute, to the costs and funding involved with course, prerequisite examination, to what career your postgraduate degree could lead to, and that's barely scraping the surface.
\end{abstract}

Keywords: data analysis,correlation,weka,parameters,stasticalanalysis, data mining

\section{Introduction}

Data mining tools predict future trends and behaviors, which allows many areas to make proactive, knowledgedriven decisions and Data mining should be performed on very large or raw datasets using either supervised or unsupervised data mining algorithms. Education data mining is emerging field of education data and data mining techniques to solved so many issues based on historical data of student's academic performance, student's learning analytic, student's behavior of course study and other factors which belongs to achieve a good ratio of enrolment in specific course. Many factors are effected the students' performance on education

\subsection{Background}

It is sometimes heard that many postgraduates have less knowledge than graduates, and if it is the better career that after graduation, education that enhances your skills becomes an important asset. That's a massive number of students unqualified for a job. These students are usually more confused, because they can't land a job to get some work experience under their belt. As said by a researchers that "Investment is higher education is high, but so are the benefits that come along with it ". Postgraduates earn higher than the graduates, and also the type of degree can decide the earning potential of a postgraduate. As per AISHE report "The student enrolment from UG going higher to PG is thus decreasing steeply". Majority of colleges are smaller in terms of enrolment. 22\% of the Colleges are having enrolment less than 100 and $40.7 \%$ of the colleges have student strength 100 to 500 which means $62.7 \%$ of the colleges enrol less than 500 students. Only $4.3 \%$ Colleges have enrolment more than 3000.This study is equally concerned with this subject, specifically, the students' performance, which explores multiple factors theoretically, assumed to affect students' performance in higher education, and finds a qualitative model which best classifies and predicts the students' performance based on related personal, academic and social factors. 


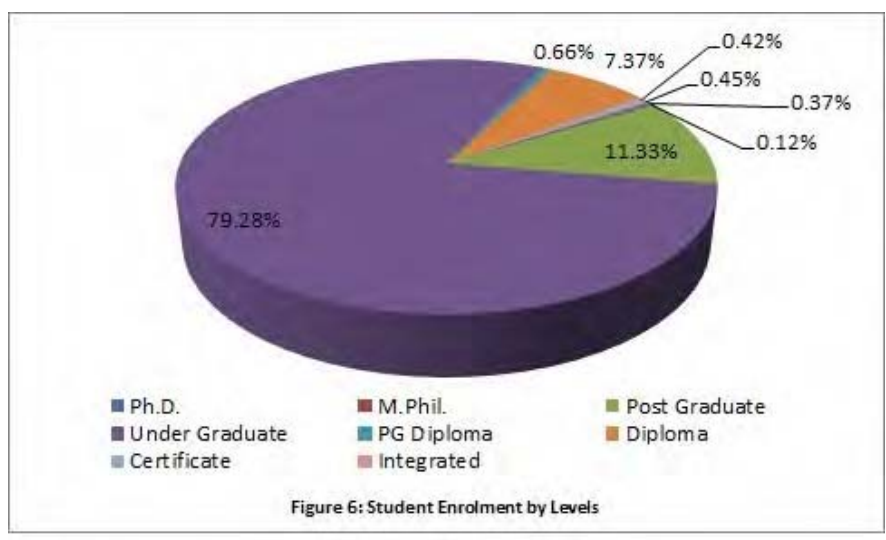

\section{Literature Survey}

A research paper is used parameters for predicting student performance using ARTMAP network as Merit in the last exam , Study by practicing examples, Average merit throughout study, Regularity in attending classes, Interest in the course, Attention in class sessions, Interest in the curriculum, Taking notes during class, Interest in learning ,Doing homework,Belief in hard work, Parents' education, Belief in learning from mistakes , Earning of the family, Study with reference books ,Financial support,Study with revision, Residential area.[1]

A research paper based on academic parameters are included for parameter selection using educational data mining. Like, Level Category,OrphanCat.,SHC Cat.,BirthYear, Camp Cat. , FatherWork Cat , ailYears ,PrevYear Cat.,FirstTerm Cat, FinalResult Cat[3] Also one of paper they are included parameters as Hrs, Regular,Library visits, books types, Interaction, time management grasping ability, extraactivites, stressmanagement, decisionmaking, prevsenresult, SLC, PUC, Hostel, facultyguide, punctual, Familyguide, HIS.[4]

Another paper has study on parameters which also predict the academic performance like factors related to both desired and undesired performance can be exploited for an effective enrolment strategy, performance associated factors can lead to an effective degree/course planning.[5] Some other researcher's used same parameters as Student's last-term GPA,Course's last-term cumulative GPA, Student's last-term cumulative GPA,Student's high school or transfer GPA,Course's last-term GPA,Credit hours attempted by student,Credit hours student is taking this term,Total historical course enrolment, Student zip code,Instructor classification[6]

Also some papers shows in categorywise parameters for student's academic performance prediction based on Gpa,Pass_Hra,Finish_Hra,Total_Reg_Hrs,Still_Hrs,Register_Hrs, Descen, English_Level, Faculty_Nameen, Schoolbranches_Descar,School_Avg, School_YYear for Arabic higher education institute to develop an intelligent decision support system.[7]

In this, some papers are focus on dropout ratio based on some parameters as category Demographical:Gender, State, Age,Ethniicity ,BMI, community, disability,workstatus,type of school,family income, family motivation,familycontrol,familyeducation,selfconfidence,Marital status, no. of children, student job,student funding/scholarship etc..Geographical:Palce of residency, location of institute, Institute type etc...Course: course,course result/marks/grade, study timing,studyduration,studygroup,Institute /teaching environment, Attempt count, seminar performance ,assignment grade, lab performance, computer literacy etc...Dependent: student outcome, dropout.[8]

Many researchers studied in various aspects of student's factors for career selection as a post graduate course. Here are the numbers of factors using by various researchers on past years:Also some research papers included predicting Academic Performance with Pre/Post Enrolment Factors using data mining techniques:

1. Predicting students" performance in internal tests and semester end exams. makes the faculty to follow or improvise certain course conduction methodology by 2017, Parkavi A, K. Lakshmi, K.G. Srinivasa

2. Predict student's academic performance based on students' data (social an academic attributes) by 2017, Hafez Mousa, Ashraf Maghari

3. Students performance prediction based on student academic result using SVM technique by 2017 , Mrs.M.Jamuna.,Mrs. S.A.Shoba.

4. A study on the result based analysis of student performance using dataMining techniques by 2017 , E.Venkatesan, S.Selvaragini,

5. A review paper on Prediction analysis: predicting Student result on the basis of Past result by 2017, Priyanka Dhamija, RainuNandal,HarkeshSehrawat 
6. Student's performance prediction model using student academic examination data set using decision tree ,fuzzy genetic algorithm by 2016, HashmiaHamsa, simiindradevi, J. Kizhakethottom.

7. Performance Analysis and Prediction in Educational Data Mining: A Research Travelogue by 2015,PoojaThakar, Anil Mehta, Manisha as a survey paper.

8. Graphically represented Institutional Growth Prognosis and Students' Progress Analysis using naïve bayes algorithm by 2014, Saranya, S., R. Ayyappan, and N. Kumar,

9. Found predicting model for academic performance that is user friendly for professors or non-expert users.using Chi-Square Test, One R-Test, Info Gain and Ratio Test, Naive Bayes, DTree by 2012, Osmanbegović, Edin, and Mirza Suljić

Above mention all papers are selected parameters which related to academic ,social, economic and other parameters to predict the performance of students and make decision for grading on degree. Also various data mining techniques are used by researchers to develop a model as predictor of performance, find out weak students based on scoring on various examinations.

\section{Data analysis}

A survey is conducted using questionnaire which design to identify three main aspects, institutional factors, academic evaluation factors and social environmental factors. All the predictor and response variable are given in table for reference. The section two institutional factors has three sub sections, course information factors, course skills \& placement factors. The second section involves academic evaluation factors. The section on social personal factors has six sub sections: personal characteristics, social impact, language factors, time factor and economic factors. The domain values for the nativity variables were defined for the present investigation as follows:

\subsubsection{Category I: Institutional Factors}

When a students will start to selecting his/her career course, the most important factors are belongs to reputation of institute, what kind of diversity offering by institute, location of institute, what kind of campus facilities are provided by institute, also find whether institute provide various facilities like library, computer laboratory, wi-fi in campus, whether current students are getting opportunities in research and also promoted by faculties for same or not. Also Student will be aware whether institute avil ICT based learning methodology or not. Apart from this entire student also recommended those institute for further study in which alumni students were placed in reputed companies after completion of PG course. So these are the main factors for selecting an institute for higher study after graduation.

It is also important that when a student will select the post-graduation, there are so many possibilities are there to select proper course. For this students are selecting the course which have more preferable as market-demand approach also which helpful to enhance the skills of student while he/she will enrol in PG course. Also admission policies, procedures, prerequisite test, fees structures, seats reservation of specific course, transparency of admission, duration of course, course curriculum, stream of course past students average result, time-to time updating in course /programs, get part-time job while study in PG course.

\subsubsection{Category II: Academic Evaluation Factors}

This category are the combination of predicted and response variable. It is important and highly qualitative approach to predict the enrolment of course may be getting successive or not. For these number of factors are involved in this category like student's 12th result, result of last semester or degree, spend time for study, interest in study in current course, assignment score, attendance of each subjects, learning style of students, using of various facilities like library, Wi-Fi technology by students during the study. Also many students are interested in co-curricular activities and participated in various competitions, achievement in various events. Some course have designed graduate attributes, some institute they follow the graduate attributes skill test for whether after completion of graduate student will able to get the graduate attribute or not using some testimonial.

\subsubsection{Category III: Social-Personal/Psychological Factors}

These category is as important as above category which includes personal attributes, family attributes, kind of language known by students ,psychological factors and social impact factors whether students will able to do as per selection of course.

\subsection{Data collection:}

In this paper, we are representing parameters which highly affect the decision of students' course selection. For this we used M.Sc. Computer application students of Shree Ramakrishna Institute ,surat using questionnaires as Google form. These influencing factors are categorised as input variables. The output variables on the other hand representative some possible result. We selected following attributes which have above category for study. 


\begin{tabular}{|l|l|l|}
\hline No. & Variable & Description \\
\hline 1 & Gender & Gender \\
\hline 2 & StayLoc & Residency \\
\hline 3 & Famqua & Parent's Education \\
\hline 4 & Famincom & Annual Income of Family \\
\hline 5 & Caste & Caste of Student \\
\hline 6 & Currcourse & In currently which course study? \\
\hline 7 & Transport & Which Transportation use to reach? \\
\hline 8 & Result12 & Grade in 12th Standard \\
\hline 9 & Result_last_SEM & Last Semester/year Result \\
\hline 10 & Attendance & Attendance in class \\
\hline 11 & Interest_study & Are you interested in this course study? \\
\hline 12 & Learn_type & Which is learning type of student? \\
\hline 13 & like_study_pur & Are you influence by others? \\
\hline 14 & Stream_select & Which stream you selected? \\
\hline 15 & Whyselect & Why you select this course? \\
\hline 16 & Timespent & How much time spent for Study? \\
\hline 17 & Useict & Using internet or mobile technology for which purpose? \\
\hline 18 & Tutorial & What kind of tutorial preferred for study? \\
\hline 19 & Compknw & How much computer knowledge you have? \\
\hline 20 & Tuision & Are you need tuision? \\
\hline 21 & Kinduniv & Type of university/institute prefer \\
\hline 22 & Likecourse & Are you like currently enrolled course? \\
\hline 23 & Age & Range in years \\
\hline 24 & Pgcourse & Which Pg course you select? \\
\hline 25 & Successpg & Prediction of successive on selection of course? \\
\hline & & \\
\hline
\end{tabular}

Gender: Male/Female-This attribute consider for value as "Male" or "female". It is used to find how many female or male are enrolled in specific course. It is important to that how many females are turned for further study.

StayLoc: Locality of Residency -This attribute is important because student's residency location is said about the culture and environment which always increase or decrease interest on overall personality and behaviour of student.

Famqua: qualification of family members- This attribute shows if education literacy is there then its always motivated to children and inspired of other family members. So, it is also a attribute which consider as socialpersonal category.

Famincom: annual income of family members- This attribute is considered for the purpose of fees affordable to family or not. Now a days financial matter is also important for selection of course on private institute. . So, it is also a attribute which consider as social-personal category.

Caste: Open/SC/ST/OBC-When any students want to take admission in any course and he /she belongs to reservation category, they always search for the seat reservation category is follow or not. So may be its chance that if income of family low or result/grade criteria followed by University/Institute.

Currcourse: Current course selected by student for study- This attribute said for already enrolled in any graduation course. It is helpful for find which graduate course stream or medium of students' presently selected.

Transport: Transport facilities -It is important that students' travelled when they are studies and also check the distance from residency to selected institute, how much time and financial matter affect their selection. Also Its also impact on overall academic performance of students.

Result12: 12 th standard result which is distinction: $>=70 \%$, first: $70<$ per $>=60 \%$, second: $60<$ per $>=50 \%$, pass: $50<$.per $>40 \%$,otherwise Fail grade. This attribute is important for enrol in any course.

Result_last_sem:Seemster/year result which is distinction: $>=70 \%$, first: $70<$ per $>=60 \%$, second: $60<$ per $>=50 \%$, pass: $50<$.per $>40 \%$,otherwise Fail grade, A.T.K.T. $<=35 \%$ or marks below $35 \%$ on any subject. This attribute is important for enrol in any course. Now a days CGPA/SGPA is also used for result grading, but we are using percentage as above. 
Attendance: Class or Laboratory attendance- Attendance attribute for punctuality of students in class or laboratory which shows the sincerity and interest towards subject or course in which he/she is enrolled.

Interest_study: This attribute is important as student's like or dislike the course and overall environment enjoyed in which he/she is already enrolled.

Learn_type:Style of Learning - This attribute is used to show that which is the ability of students' to grace their knowledge in class. Physically appearance in a class is a part of it. But important is that how students' thinking. As this is psychological factor which is included in this study.

Like_study_pur: The purpose of this attribute is shows for More Interest to get knowledge in specific area, Job purpose or both. As this is psychological factor which is included in this study.

Stream_select: Many institutes is running different stream like Science, commerce, Arts , Engineering or others. Many course curriculum is designed by statutory board for specific course stream only.

Whyselect: Students may be choose course for either higher requirement of market /bussiness demand or after discuss with friends/parents for selection course or they choose their own Choice. It is an important psychological factor which belongs to inspired or influence by others for any decision making process.

Timespent: Time spent for study- For study in any course, it is important that how much time spent for their study. As this is environmental factor which is included $i$

Useict:Usage of Internet/wifi/Communication technology- The use of ICT for either search \& download subject related notes/Videos/articles, Most time for entertainment \& less time for study, Chatting/surfing/entertainment /download movie/songs or None. This attribute helps to identify the interest of students' towards ICT usage.

Tutorial: Tutorial used for study-Sometimes for study and communicates with others, your own class notes /Made by your self, your friends note/tusion class notes. This attribute is helpful for academic evaluation. It is academic performance factors which very important.

Compknw: Nowa days every course initial required some knowledge about computer. It is as much important as use of technology for study. Here in this analysis, we included only of computer science/information technology/Application students .It have strong correlation shows in analysis.

Tuision: Sometimes students required extra classes for good academic appearance. this attribute also helpful for find out remedial classes are required by students' or not. So this attribute also important to decrease dropout ratio if we will found that students required more attention.

Kinduniv: there are many type ot university/Institute now a days offering many different kind of courses. This attribute is important for selection of course. For this, we will include type of university, affiliated college/Institute, various courses offered by colleges with the help of AISHE[All India Survey on Higher Education] reports available in www.aishe.nic.in . Recently institute website is helpful for course information. Students' are selecting course based on above attribute but also this attribute is very much important in this study.

Likecourse:Students' like enrolled course because of some reason like locationwise, Quality of course, Popularity of course, All or any two from above, None etc. So, It is a support factor for my research.

Age: Age of student- this attribute is helpful for check compatible for course or not. This attribute is helpful for placement of students after degree awarded as age criteria also a part for job placement.

Pgcourse: Many courses are offered by colleges, here we are giving the selection of course for prediction.

Successpg: This is out dependent factor which used to make final decision for above selected course will identify benefit to student for career platform.

\section{Statistical Analysis}

To apply data mining technique, each parameter has to be evaluated statistical methods and find correlation between them. Uses of these parameters are helpful to find its impact on final result. In weka tool, we applied data cleaning, data missing filters applied on student data set. For feature evaluation of attribute GainRatioAttributeEval and CorrelationAttributeEval methods are used. The experiment shows that academic evaluation factors, psychological factors and social personal factors are strong correlation $\mathrm{r}, 1<\mathrm{r}>1$.

\begin{tabular}{|l|l|}
\hline Gain Ratio (Rank) & Attribute NameEvalutor: GainRatioAttributeEval, Search: Ranker Method \\
\hline $1-4$ & Pgcourse, Useict, Compknw, Kinduniv \\
\hline $5-9$ & Famincom, Whyselect, Tutorial ,Likecourse, Caste \\
\hline 10-24 & $\begin{array}{l}\text { Currcourse, gender, Age, StayLoc, result_last_sem,timespent, result12, interest_study, } \\
\text { like_study_pur,transport,famqua,tusion, stream-select,learn-type, attendance }\end{array}$ \\
\hline
\end{tabular}


For another Correlation attribute evaluator gives following result for ranker search method:

\begin{tabular}{|l|l|}
\hline Gain Ratio (Rank) & Attribute NameMethod: CorrelationAttributeEval Search: Ranker Method \\
\hline $1-4$ & Kinduniv, compknw, pgcourse, useict \\
\hline $5-9$ & Whyselect, famincom, tutorial, gender, likecourse \\
\hline $10-24$ & $\begin{array}{l}\text { Currcourse,stayLoc,Interest_study,tusion, caste, age, timespent, transport, } \\
\text { like_study_pur, learn-type, result12, stream_select, Result_last_sem,attendance,famqua }\end{array}$ \\
\hline
\end{tabular}

\section{Conclusion \& Future Work}

As a part of conclusion, here we have gathered the most affecting parameters for the student's for higher education study. In this study right now, we are added parameters for academic evaluation and personal attribute. Now we will add the institutional placement parameters in our study which also affect the enrolment ratio on post graduate course and also its helpful for better performance. Also the proposed work, in our next paper we will test each parameter against the model.

\section{References}

[1] AroraNidhi, Jatinderkumar R. Saini ,Predicting Student Academic Performance using Fuzzy ARTMAP Network, International Journal of Advances in Engineering Science and Technology, ISSN: 2319-1120

[2] A. Parkaviand K. Lakshmi ,Pattern Analysis of Blooms Knowledge Level Students Performance using Association Rule Mining, 2017 IEEE International Conference on Smart Technologies and Management for Computing, Communication, Controls, Energy and Materials (ICSTM),VeltechDr.RR\& Dr.SR University, Chennai, T.N., India. 2 - 4 August 2017. pp.90-93.

[3] Layla Safwat Jamil, Data Analysis Based On Data Mining Algorithms Using Weka Workbench , International Journal Of Engineering Sciences \& Research Technology,ISSN: 2277-9655, Jamil* et al., 5(8): August, 2016

[4] Hafez Mousa1, Ashraf Maghari ,School Students' Performance Predication Using Data Mining Classification , International Journal of Advanced Research in Computer and Communication Engineering ISO 3297:2007 Certified Vol. 6, Issue 8, August 2017 ,Copyright to IJARCCE DOI10.17148/IJARCCE.2017.6824 136

[5] Parkavi A, K. Lakshmi, K.G. Srinivasa ,Predicting effective course conduction strategy using Datamining techniques , Education research and Reviews , Vol. 12(24), pp. 1188-1198, 23 December, 2017 , DOI: 10.5897/ERR2017.3266 , Article Number: 8CACD3D67014, ISSN 1990-3839 Copyright (C) 2017

[6] Sayali Rajesh Suyal, Mohini Mukund Mohod,Quality Improvisation Of Student Performance Using Data Mining Techniques , International Journal of Scientific and Research Publications, Volume 4, Issue 4, April 20141 ISSN 2250-3153

[7] Shruthi P, Chaitra B P ,Student Performance Prediction in Education Sector Using Data Mining , International Journal of Advanced Research in Computer Science and Software Engineering, Volume 6, Issue 3, March 2016 ISSN: 2277 128X

[8] Sateesh Gouda M, Dr.T.V.Sekher, Factors Leading to School Dropouts in India: An Analysis of National Family Health Survey-3 Data,I OSR Journal of Research \& Method in Education (IOSR-JRME)e-ISSN: 2320-7388,p-ISSN: 2320-737X Volume 4, Issue 6 Ver. III (Nov -Dec. 2014), PP 75-83.

[9] ThakarPooja , Anil Mehta, Manisha,Performance Analysis and Prediction in Educational Data Mining: A Research Travelogue , International Journal of Computer Applications (0975 - 8887) Volume 110 - No. 15, January 2015

[10] T.Archana and Usha Devi Gandhi , Prediction Of Student Performance In Educational Data Mining - A Survey , T.Archana* et al. International Journal of Pharmacy \& Technology , ISSN: 0975-766X, Accepted on 29-08-2016

[11] UndaviaJaimin,AtulPatel,Shah Nikhil,Education Data Mining - A Prediction Model and Its Affecting Parameters for Prediction in Higher Education, International Journal of Engineering Research \& Technology (IJERT), Vol. 1 Issue 7, September - 2012

[12] V.Ramesh, P.Parkavi , K.Ramar , Predicting Student Performance: A Statistical and Data Mining Approach , International Journal of Computer Applications (0975 - 8887) Volume 63- No.8, February 2013

[13] Online Reports of AISHE website: www.aishe.ac.in 